\title{
Las razones de Don Braulio, o el realismo popular venezolano como problema historiográfico
}

\section{The Reasons of Don Braulio, or the Venezuelan Popular Royalism as a Problem}

TomÁs STRAKA ${ }^{1}$ http://orcid.org/0000-0001-8252-8033

${ }^{1}$ Universidad Catolica Andres Bello Academia Nacional de la Historia Av. Teheran, Caracas, Distrito Capital 1020, Venezuela thstraka2@gmail.com

RESUMEN El presente artículo plantea algunos problemas históricos e historiográficos sobre el realismo popular venezolano. Basándose en la idea de que su importancia fue fundamental en el moldeamiento del Estado-nación, tanto por los desafíos que impuso a los republicanos, como por los fenómenos sociales que expresó, subraya la escasez de estudios sobre el tema y trata de ofrecer algunas alternativas para su investigación. Para ello toma las memorias de un soldado realista, Braulio Fernández, para a través de sus ideas y omisiones, identificar algunos tópicos que caracterizaron al realismo popular, que sirvan de guía para futuras investigaciones.

Palabras Clave realismo popular, guerra de independencia, Venezuela - historiografía, Braulio Fernández 
ABstract This article presents some historical and historiographical problems posed by Venezuelan popular royalism. Based on the idea that this movement of critical importance in the Venezuelan nation-state's construction, because of the challenges that it posed for republicans as well as the social phenomena that it involved, this paper highlights the lack of studies about this issue and offers some alternative approaches to it. The autobiography of a royalist soldier, Braulio Fernández, is analyzed to identify some features of popular royalism, that can guide further research. KEYWORDS popular royalism, independence war, Venezuela - historiography, Braulio Fernández

\section{INTRODUCCIÓN}

El objetivo del presente trabajo es plantear en términos históricos e historiográficos el problema del realismo popular en Venezuela. Aunque existen algunos trabajos sobre los grupos realistas de las elites (Straka, 2000; Lombardi, 2006; Lovera, 2007; López, 2010), su expresión en otros sectores populares, es decir, en palabras de Eric Van Young, "la gente humilde y los cuadros de mando de los niveles medio y bajo", distinto al "grupo de liderazgo criollo y mestizo" (Van Young, 2010, p.365), apenas ha sido tocado por la historiografía (Cañizales Guédez, 1993; Berrueta; Arismendi, 2011). Eso significa que estamos ante una carencia importante, porque se trata de la mayor parte de quienes apoyaron al Rey durante la Guerra de Independencia, e incluso de la población general de Venezuela hasta, por lo menos, 1820. El principal sostén que tuvo el realismo en el país estuvo en ese espectro de la población, al punto de que la pérdida de su respaldo significó, en gran medida, la derrota de los partidarios de la unión con España en Venezuela. Por si fuera poco, en la configuración de ese realismo es posible identificar muchas de las tensiones sociales y de los valores que caracterizaron al país hasta entrado el siglo XIX.

En efecto, el papel de esas tensiones y valores fue clave durante todo el proceso de formación y consolidación de la república. Desde que se 
rebelaron mayoritariamente en contra de ella en 1812 y sobre todo en 1814, destruyéndola; hasta la agitación social que definió sus primeras décadas después de la separación de la llamada Gran Colombia en 1830, uno de los desafíos más grandes a los que tuvieron que enfrentarse las elites fue el del control de la sociedad y un territorio para encauzarlo en su proyecto. Por esa razón, para bien o generalmente para mal, el pueblo fue traído a colación en las reflexiones e investigaciones sobre la historia venezolana. Todo el discurso anti-popular que se desarrolló durante el siglo XIX, al que Elías Pino Iturrieta ha denominado la tesis del "pueblo inepto" (Pino Iturrieta, 1993, p.187-201), respondió a ello: las elites, ante la imposibilidad de controlar la situación y hacer de la república lo que soñaban, le endilgaron la culpa a un pueblo incapaz, que por ello no puede gobernarse a sí mismo. En la contemporaneidad eso fue cambiando en las ciencias sociales, que invirtiendo la ecuación han identificado el problema más bien en la debilidad de esos grupos dirigentes (Urbaneja, 1978; Pino Iturrieta, 2001); hasta llegar a un discurso que yendo al otro extremo, convierte al pueblo en el nuevo héroe colectivo de la historia y a las elites en las responsables de todos los males (Bolívar y otros, 2010). Lo que ha ocurrido poco es el esfuerzo por dejar hablar a esos sectores populares con su propia voz; entenderlos desde sus razones.

Las siguientes páginas esperan problematizar este asunto desde una perspectiva histórica e historiográfica. Tomaremos como eje a un texto que ha adquirido cierta notoriedad en Venezuela, las memorias de Braulio Fernández (1791-1887), recientemente llevadas al cine en 2012 con el título de Memorias de un soldado, del realizador Caupolicán Ovalles, hijo. Aparecido como un folleto en Píritu en 1887 (Imprenta La Voz de Oriente), consiste en los recuerdos uno de esos mandos medios de los que habla Van Young, recogidos por sus hijos cuando ya frisaba sus 95 años y sacados a luz poco después de su muerte. Por eso es un testimonio casi único. Pocas veces hallamos la historia contada por un soldado de la tropa; además, al ser transcrita por personas que evidentemente no tenían una formación literaria, mantiene un lenguaje coloquial que hace sentir que casi se está oyendo a Don Braulio, como 
seguramente lo llamaban todos, en su casa en el pueblo de Anaco. Pero el texto también es revelador porque su vida militar y política es emblemática de la de las mayorías de los venezolanos de su época: comenzó en las guerrillas realistas y terminó en las del Partido Liberal. Esa continuidad aparentemente inverosímil de pasar de amar - literalmente, esa era la palabra que se usaba - a Fernando VII, a seguir, tres décadas después, al líder, más bien democrático-radical, Antonio Leocadio Guzmán, parece haber sido muy común, ya que ambos contaron con los apoyos de los mismos sectores sociales. En el caso de Fernández tenemos el testimonio de uno que vivió lo suficiente para seguir todo el itinerario y además contarnos cómo lo hizo. Eso demuestra la manera en la que los sectores de la base de la pirámide social negociaron su apoyo a los distintos bandos con base en sus intereses, por lo que el hilo conductor entre el realismo popular y el liberalismo popular venezolano hay que buscarlo en ellos y no en las ideologías y partidos con los que se alinearon en determinados momentos.

Advertimos que Don Braulio no hace consideraciones ideológicas. Hay que entresacar de lo que dice y de lo que calla, que no es poco, sus actitudes. El brevísimo texto se centra en lo que al parecer fue para él, o para sus hijos, que a lo mejor expurgaron sus recuerdos, el hecho fundamental de su vida: el avance hacia Caracas que en 1821 emprende desde Oriente el General José Francisco Bermúdez, mientras Simón Bolívar hacía lo propio desde los llanos occidentales. Bermúdez toma brevemente la capital, pero tiene que retirarse por un contrataque. No obstante, esta acción obliga a los realistas a desviar parte de sus tropas hacia el Este, cosa que ayudó al gran triunfo de Bolívar en la Batalla de Carabobo. En la actualidad a todos los venezolanos se nos enseña en la escuela que la batalla de Carabobo selló nuestra independencia, y el 24 de junio es una fiesta cívica (fecha patria, es la categoría que se usa), que conmemora a la acción bélica y celebra el Día del Ejército. Como para el momento en el que se escriben las memorias ya lo fundamental de esta interpretación de la fecha estaba oficializada, resulta razonable pensar que a Don Braulio (o a sus hijos) le pareció singularmente importante esta participación en un hecho cumbre de la Historia Patria; pero nosotros echamos de 
menos una explicación sobre sus cambios de bando y sobre palabras que usa - "Corona", "Libertad" - pero que no sabemos exactamente qué significaban para él. Por eso insistimos en que él nos permite sobre todo delinear un problema, más que avanzar especialmente en su elucidación. El folleto autobiográfico llegó a las manos del abuelo del cineasta, el escritor y bibliófilo venezolano Víctor Manuel Ovalles (1860-1955), y fue sacado a luz por su padre, el poeta Caupolicán Ovalles (1936-2001), en su Antología de la literatura marginal (1977).

Dividiremos el trabajo en tres partes: primero, una visión general del problema de la participación del pueblo en la independencia y el desafío que eso ha representado para la memoria de los venezolanos. Como veremos, es un tema historiográfico, pero con tales implicaciones políticas, que sirve de ejemplo para estudiar el tema de las políticas de la historia. En segundo término, nos detendremos en lo que envolvió y fue determinante para muchos de los suyos, el de la igualdad como una de las fuerzas motrices del accionar político popular, y que explica una vinculación en principio tan inverosímil como la del realismo con el liberalismo democrático. Y por último, pondremos a dialogar estas dos cosas con lo que se cuentan en las memorias, para tratar hacernos una idea más clara de su pensamiento y de los retos que implica analizar el realismo popular en términos generales.

Es necesario advertir que este trabajo no aspira más que al planteamiento muy preliminar del problema. Sabemos que es indispensable enmarcar las memorias que servirán de eje a este trabajo dentro de una investigación documental más amplia. Ya en lo referente al tipo de documento en sí, también sería necesario su cotejo con otras memorias, como por ejemplo las compiladas por el historiador Manuel Hernández González de canarios que vivieron en Venezuela durante el período y que tendieron a formar parte del realismo popular, muchas veces en posiciones de liderazgo (Hernández González, 2010). También se requeriría un estudio comparativo con otros realismos populares, en especial los de la actual Colombia, con los que terminó existiendo un relativo vínculo debido a que formaron parte de una misma república, combatiendo por lo tanto a unos mismos ejército y Estado. La mirada 
del fenómeno desde su costado neogranadino resulta, cuando menos, otra de sus caras (Gutiérrez Ramos, 2007; Echeverri, 2009). Es por todo ello, que el alcance es el de plantear algunas cuestiones teóricas y metodológicas que sirvan de base a futuras investigaciones.

\section{SObRe El PROBLEMA DEL PUEBLO}

\section{EN LA HISTORIA VENEZOLANA}

El proceso de nacimiento y consolidación de la república venezolana es el que ha recibido, de lejos, más atención por parte de la historiografía. Tanto en su etapa pre-profesional, cuando la idea de la Historia Patria se asociaba sólo a la del ciclo de la emancipación (1795-1830), como en la posterior, los años que van de la declaración de la independencia en 1811 hasta la toma definitiva del poder por el Partido Liberal Amarillo y su caudillo Antonio Guzmán Blanco en 1870, concentran la mayor parte de lo escrito y pensado sobre el pasado venezolano. Naturalmente, en esta multitud de estudios hay diferencias muy importantes entre los distintos enfoques y corrientes. No puede meterse en un mismo saco a lo escrito en el siglo XIX con el objetivo de crear una épica que legitimara al nuevo Estado, con las revisiones críticas de los positivistas a principios de la centuria siguiente o las que se han hecho desde la década de 1960, sobre todo en lo referente a la carga ideológica del llamado Culto a Bolívar y su función como ideología del Estado (Carrera Damas, 1970; Castro Leiva, 1984; Franceschi, 1999; Pino Iturrieta, 2003; Torres, 2009; Straka, 2009). Aunque puede afirmarse que en la actualidad (escribimos en 2018) es mucho lo que se ha avanzado en la comprensión del período, aún quedan aspectos que son un terreno relativamente virgen para la investigación, como el de su perspectiva "desde abajo", es decir, desde sectores distintos a los de las elites.

No obstante, lo anterior no significa que lo "popular" haya sido completamente obviado por la historiografía. Por el contrario, para bien o para mal se le ha traído muchas veces a colación. Lo hicieron los hombres de la independencia y del período inmediatamente posterior, cuando hablaron de los "pueblos estúpidos", según la frase de Simón 
Bolívar, ${ }^{1}$ a quienes atribuyeron muchos de sus fracasos; lo hicieron los positivistas, cuando alegaron que por razones de raza y de geografía era incapaz de gobernarse a sí mismo, estando condenado al mando de un Gendarme Necesario. Y lo ha hecho también el chavismo, cuando se ha propuesto "transformar la historiografía para transformar la memoria colectiva y crear una conciencia histórica que empodere al pueblo de su pasado y su presente..." y que sirva "para fundamentar el proyecto revolucionario", para bien o para mal el pueblo ha sido traído muchas veces a colación (Pellicer, 2010, p.VI). Como vemos, las interpretaciones históricas del pueblo suelen tener consecuencias políticas importantes. Lo que prácticamente no ha pasado es que se le deje hablar con su propia voz (aunque, más allá de su intencionalidad política, se ha hecho algo al respecto en Bolívar y otros, 2010).

Pero hay razones de fondo, que van más allá de lo estrictamente político-ideológico. No se trata sólo de "una historia tradicional y conservadora que ha excluido al pueblo del relato histórico y que, intencionadamente, ha invisibilizado su actuación o la ha estigmatizado culpándolo de los fracasos republicanos" (Pellicer, 2010, p.V). Eso ocurrió, sin duda, y Bolívar es acaso el mejor ejemplo; pero viendo las cosas con sentido histórico no hay razones para esperar que un historiador de 1860, 1910 o 1950 se preocupara especialmente por las visiones de los sectores populares, salvo que sea para verlos desde una perspectiva antropológica - en el sentido de la época - y siempre con el tamiz de su propia forma de entender el mundo. Carece de sentido histórico esperar posiciones distintas en épocas en las que no existían; y si hombres como Pedro Manuel Arcaya o Lisandro Alvarado hicieron otra cosa, hay que celebrarlas como afortunadas excepciones, no como parámetros para medir a sus coetáneos. Pero, además, en el caso en el que lo hubieran querido, se habrían encontrado con que las capas mayoritarias de la

1 BOLÍVAR, Simón. Memoria dirigida a los ciudadanos de la Nueva Granada por un caraqueño, escrita por Simón Bolívar en Cartagena de Indias, el 15 dic. 1812 (convencionalmente conocido como "Manifiesto de Cartagena"). En: BOLÍVAR, Simón. Escritos fundamentales. Caracas: Monte Ávila Editores, p.1-12, 1988. p.2. 
sociedad venezolana fueron iletradas hasta entrado el siglo XX y prácticamente no dejaron registros. Es una situación que ha ido cambiando desde la década de 1990, cuando las historias de las mentalidades y las cotidianidades despertaron el interés por fenómenos sociales que requirieron ampliar el espectro de los actores y las fuentes a investigar. Desde entonces, se ha avanzado en una comprensión más general e inclusiva de la sociedad, aunque no sin caer dentro de las diatribas políticas que han caracterizado a Venezuela en las últimas dos décadas. Dentro de la verdadera history war que ha impulsado la Revolución Bolivariana, la independencia y, dentro de ella, el papel del pueblo, han adquirido una dimensión política e ideológica muy importante (Straka, 2013). Uno de los ejemplos más claros es la especie de manifiesto político-historiográfico que Luis Felipe Pellicer hizo como presentación al libro Memorias de la insurgencia (2010), algunas de cuyas frases fueron citadas más arriba. Cuando mezcla aspectos como el "empoderamiento de la historia por el pueblo" (que no por toda la sociedad) o la toma en consideración de "la diversidad geohistórica, la diversidad étnica y cultural, la diversidad social y la diversidad de género", con el objetivo de "rescribir la historia para fundamentar el proyecto revolucionario" (Pellicer, 2010, p.V-VI), lleva al discurso histórico por el terreno quebradizo y resbaloso de la diatriba política pura y dura. No es de extrañar, por lo tanto, que en un ambiente tan polarizado como el venezolano, lo de rescribir la historia para fundamentar el proyecto revolucionario haya ido en menoscabo de una atención mesurada y detenida de lo que en efecto tiene de importante la diversidad geohistórica, la diversidad étnica y cultural, la diversidad social y la diversidad de género para la comprensión histórica de la independencia.

Las Memorias de la insurgencia, que fueron repartidas gratuitamente y rápidamente se convirtieron en una de las banderas de la celebración del bicentenario de la Independencia en 2010, están formadas por un conjunto de expedientes de juicios de infidencia - es decir de rebelión al Rey - a venezolanos pertenecientes a los sectores populares. En sí misma, la compilación constituye un aporte. Según Pellicer, ellos demuestran "el carácter popular de la independencia", la forma en la que los 
pardos y las mujeres contribuyeron a su alcance (Pellicer, 2010, p.IX-XII), lo que no deja de ser importante. Pero recordemos que a Pellicer le preocupa sobre todo fundamentar a la Revolución Bolivariana. El historicismo político bolivariano, como definió a este fenómenos sociocultural Luis Castro Leiva (1984), que es una de las bases del proyecto chavista como lo ha sido de casi todos los regímenes venezolanos desde la década de 1870, cuando Guzmán Blanco oficializó el Culto a Bolívar, tiene con el pueblo un escollo: comoquiera que según ese historicismo todo cuanto ha de hacerse debe responder a los dictados del Libertador, ¿cómo alegar en 2010 que a la vez se es bolivariano, democrático y socialista, cuando el pueblo fue básicamente opuesto a Bolívar y éste en consecuencia siempre manifestó muy poca confianza por él? No se nos malinterprete, no es que Bolívar no haya sido un revolucionario que empujó las cosas hacia niveles de libertad e igualdad mucho mayores a los del régimen colonial; al contrario, quien defendió la abolición de la esclavitud, la libertad económica y la supresión del sistema de castas, por sólo nombrar tres cosas en las que terció directa o indirectamente, tiene en este aspecto la balanza a su favor. Pero al mismo tiempo manifestó todo el tiempo la necesidad de llevar todas esas transformaciones desde arriba, por un gobierno más o menos aristocrático (Carrera Damas, 2003; Guerrero, 2004; Urbaneja, 2004; Lynch, 2006; Urueña Cervera, 2007).

Tiene razón Pellicer cuando afirma que al pueblo se le ha culpado de los fracasos republicanos y que se le ha acusado de ser "un obstáculo en la construcción de la nación" (Pellicer, 2010, p.V). Eso ha sido así, primero, porque Bolívar mismo lo pensó de esa manera y dentro del historicismo político bolivariano cualquier idea del Libertador debe ser aceptaba como buena; en segundo lugar porque a las elites y dictadores que gobernaron mucho tiempo Venezuela la idea del "pueblo estúpido" les venía muy bien, ya que los hacía indispensables para conducirlo, y finalmente porque, en efecto, el pueblo venezolano se rebeló contra la república, haciéndola sucumbir al menos dos veces (al respecto es iluminador el trabajo de Carlos Pernalete Túa, 2011). Pellicer trata de rescribir la historia - recordemos que es la palabra que usa - pero tiene frente a sí a dos valladares muy grandes: las evidencias documentales 
y la necesidad de no salirse del historicismo político bolivariano, a los que mutuamente se siente obligado a someterse. Al final opta por el viejo expediente de calzar los hechos, a la fuerza si es necesario, a lo que dijo Bolívar. O en su caso, de obviar simplemente lo que dijo al respecto. Por el contrario, la "historia tradicional y conservadora" del siglo XIX, aunque igual (o tal vez un poco menos) intencionada que él, tuvo al menos a su favor la evidencia y la palabra, siempre inapelable, del Libertador. Por ejemplo, en el Catecismo de historia de Venezuela de Rafael María Baralt y Manuel M. Urbaneja, de 1865, se le explica a los niños que en el bando patriota estaba "lo más granado de la sociedad, ricos é ilustrados"; mientras a la pregunta de "Y el pueblo á qué partido se inclinaba?", respondía: "fluctuaba por lo general entre sus hábitos perezosos y serviles, y su deseo innato de novedades". Ese mismo año Juan Vicente González espeta la famosa frase de que José Tomás Boves, el líder de la rebelión popular y antirrepublicana de 1814, es el "primer jefe de la democracia venezolana." ${ }^{3}$ Es una visión antipopular a la que el positivismo le creyó dar, dos décadas más tarde, un carácter científico con sus teorías de raza y clima.

Pero quedémonos con González. Escribía a dos años de concluida la Guerra Federal (1859-1863), el más grande de los conflictos que se escenificaron en la etapa de inestabilidad que vivió Venezuela entre 1858 y 1870. Cuando González, que era una de las grandes figuras del llamado Partido Conservador, decía en aquel contexto que en la anarquía, los saqueos y las matanzas de blancos impulsadas por los hombres de Boves en 1814 estaba la "democracia venezolana" en su primera versión, cualquiera de sus lectores podría identificar rápidamente la similitud con los desórdenes que habían ocurrido en la reciente guerra civil, cuando

2 BARALT, Rafael María; URBANEJA, Manuel M. Catecismo de historia de Venezuela. Desde el descubrimiento de su territorio en 1498, hasta su emancipación política de la monarquía española en 1811 (1865), p.225. En: CARRERA DAMAS, Germán. Historia de la historiografía venezolana (textos para su estudio). 2da. edición. Caracas: Universidad Central de Venezuela, p.201-227, 1996.

3 GONZÁLEZ, Juan Vicente. Biografía de José Félix Ribas. Caracas: Colección Libros, Revista Bohemia. Caracas: s/f, p.206. 
el pueblo vuelve a alzarse, ahora bajo la bandera del Partido Liberal y su discurso a favor, entre otras cosas, de la democracia. El punto, sin embargo, es que aun cuando González era intencionado en su narración, no completamente desencaminado. Para entonces un Braulio Fernández de 75 años, una edad muy avanzada entonces, y se encontraba entre los oficiales triunfadores del bando liberal. Justo medio siglo atrás, siendo un muchacho, había peleado en el mismo bando de Boves. Aunque no debieron haber sido demasiados los soldados de 1814 que volvieron a pelear en la Guerra Federal, en Fernández se ve cómo eso que González llamó "democracia" (pueblo, tumulto, desorden) es el vaso comunicante entre el realismo popular de 1814 y el liberalismo popular que empieza a perfilarse en los años cuarenta.

Viendo a González y a Pellicer se puede entender por qué Don Braulio optó por hablar poco del asunto. Si en 2010 ejecutorias como las suyas aún era un motivo de diatribas, ¡cómo lo habría sido cuando aún quedaban vivos algunos protagonistas y lo estaban casi todos sus hijos y nietos! Afortunadamente, la historiografía también ha producido explicaciones más atentas a comprender que a llevar agua al molino de alguna bandería política.

\section{SOBRE EL PROBLEMA DE LA IGUALDAD}

La republica venezolana tuvo un largo y complejo proceso de formación. Aunque fue la primera de Hispanoamérica en constituirse como tal en 1811; a partir de allí necesitó más de un siglo para que su institucionalidad funcionara de manera relativamente eficiente. Para calcular la dimensión del reto que implicó construir el Estado, basta recordar que entre 1810 y 1830 Venezuela desapareció dos veces (primero en los hechos, fragmentada en varios Estados; y después legalmente con su integración a la Gran Colombia). El proceso de independencia, que en toda Hispanoamérica tuvo connotaciones traumáticas, en Venezuela alcanzó unos niveles de violencia y destrucción poco comunes, incluso para los estándares del momento. El colapso de la corona española desató una tormenta perfecta debido a que desaparecieron las contenciones 
institucionales que hasta el momento habían atajado las tensiones sociales. Es decir, tan pronto se rompió el consenso ante la legitimidad de los gobiernos que se disputaban el poder en la península, la ausencia de un árbitro generalmente aceptado hizo que los conflictos socio-raciales e inter-regionales que venían perfilándose desde finales del siglo XVIII, y que en conjunto permiten hablar de una crisis general de la sociedad colonial (Carrera Damas, 1983; Soriano de García Pelayo, 1988; Straka, 2011), desembocaran en un conflicto armado. Una crisis en las que se jalonaban distintas luchas por la libertad - la de los esclavos por emanciparse, la de los criollos por autogobernarse $-\mathrm{y}$, sobre todo, igualdad, como las sostenidas por los pardos por acceder a los privilegios que eran coto de los blancos (Carrera Damas, 1983).

En un principio el pináculo social de terratenientes y comerciantes criollos caraqueños procuró reconducir el control en sus manos (Vaamonde, 2009), pero a ello rápidamente se opusieron los sectores de color, genéricamente conocidos como pardos, que en algunos casos se había enriquecido, pero que en todos aspiraban a la igualdad con ellos; y las elites regionales que se oponían a la subordinación a Caracas. La solución del sector de la elite que se impuso finalmente en la capital fue declarar en 1811 la separación de España, crear una república que ofreciera algunas ventajas a las mayorías (por ejemplo con la supresión del sistema de castas y de los títulos nobiliarios), impulsar la libertad económica y un sistema federal para garantizar un mínimo de armonía entre las regiones. Aunque parecía una propuesta más o menos razonable, no sólo no logró atajar la guerra civil que ya había estallado con las regiones que se negaron a seguirla, alegando fidelidad a la Regencia; sino que la misma rápidamente adquirió una connotación racial. Los pardos, los indios e incluso los esclavos prefirieron las autoridades metropolitanas a las caraqueñas, en parte por un sincero amor al Rey, y en parte porque estas habían sido el fiel de la balanza en sus conflictos con la elite criolla, razón por las que las preferían como una especie de mal menor (Castellanos Rueda; Caballero Escalona, 2010).

La combinación de las tensiones regionales y de los conflictos étnicos con el problema político de la separación de España y la adopción del 
republicanismo, se tradujo en una verdadera hecatombe. Para 1813 el territorio de Venezuela había fragmentado en cuatro pedazos: la Provincia de Maracaibo, que es segregada como una Capitanía propia y fiel a Cádiz; el llamado Estado de Venezuela en el centro del país, controlado por Simón Bolívar; el Estado de Oriente; y la Provincia de Guayana, que seguía aceptando a los gobiernos de la península. Seis años después, en 1819 , el conflicto no había terminado, pero sí dado algunos virajes importantes: ahora eran el centro y el oriente del país los que estaban bajo control del ejército español (uno enviado de la Metrópoli para eso) y Guayana la independiente. Allí se reúne un parlamento con el nombre de Congreso de Venezuela que, entre otras cosas, decide la disolución del país y el nacimiento de una nueva nación (es la palabra que usan), con la unión con la Nueva Granada. Conocida por la historiografía como Gran Colombia - en realidad se llamó República de Colombia - tuvo el éxito de ganar la guerra en su territorio y en Perú, pero al costo de quedar exhausta y de no poder atajar sus contradicciones internas. Así, la unión grancolombiana naufraga en 1830, cuando los territorios de la Antigua Venezuela deciden separarse y reconstituir un Estado de Venezuela. Por casi dos décadas el ensayo pareció funcionar bien, hasta que en el contexto de las elecciones de 1846 comenzó a manifestarse una crisis que finalmente estalla en 1858, dando inicio a otro ciclo de anarquía de doce años. Vuelve a ensayarse un modelo federal, ocurren nuevos intentos de secesiones territoriales e incluso cobra fuerza la tesis de reunificarse con la Nueva Granada para constituir en una nueva Gran Colombia. La llegada al poder de una nueva generación de políticos y hombres de negocios en 1870, logra, bajo el liderazgo de Antonio Guzmán Blanco, frenar el proceso de desintegración de Venezuela, pero en una combinación de setenta años de autocracias liberales, que si bien logran consolidar la unidad nacional y sienta las bases institucionales y jurídicas de un Estado liberal, en la práctica fueron dominadas por una alianza de caudillos, elites regionales, intereses económicos extranjeros y la serie de dictadores que controló al país (Carrera Damas, 1988; Caballero, 1995; Straka, 2013).

Pero esta fue sólo una de las aristas del problema. La "guerra de colores" (es decir racial) terminó de quebrar el orden social. Tanto entonces 
como en la actualidad hay consenso en considerar que el caso venezolano fue el más cercano al de Haití de todos los de la América Española. Esa "guerra de colores", incluso, parecía estar abriendo el camino a lo que Simón Bolívar denominó pardocarcia:

La igualdad legal no es bastante por el espíritu que tiene el pueblo, que quiere que haya igualdad absoluta, tanto en lo público como en lo doméstico; y después querrá la pardocracia, que es la inclinación natural y única para exterminio después de la clase privilegiada. ${ }^{4}$

Ya en testimonios coetáneos, como el del Padre José Ambrosio Llamozas y el de José Francisco Heredia, se demuestra que había claridad en que el realismo popular respondía a impulsos distintos de los de aquellos que defendían la causa del Rey desde una postura más doctrinal e institucional. Aunque había amor y cierto sentido de lealtad por el monarca, lo que se esperaba alcanzar luchando en su defensa no coincidía realmente con lo que en Madrid o en Caracas pensaban las autoridades y simpatizantes. Como agudamente lo entendió Heredia, su principal líder, José Tomás Boves, era un "verdadero insurgente con la voz del rey", 5 porque a su modo él y los suyos habían abolido en la práctica las instituciones de la monarquía y querían hacer una transformación de la sociedad (Carrera Damas, 1991). Conquistar el poder y obtener la igualdad con los blancos, o incluso su completo desplazamiento, no era algo que estaba en la mente de Fernando VII, pero sí de los llaneros, indios y esclavos que decían pelear por él en Venezuela. La rebelión que en 1814 lidera Boves - quien no era pardo, sino asturiano, pero supo ganarse a las mayorías - fue el punto más alto de este realismo popular. La ola de saqueos, masacres (generalmente raciales) y combates, hizo desaparecer pueblos enteros y dislocó el orden colonial de forma

4 BOLÍVAR, Simón. Carta a Francisco de Paula Santander, Lima, 7 abr. 1825, Caracas, s/f, p.116. Obras completas, Tomos II. Caracas: Librería Piñango.

5 HEREDIA, José Francisco. Memorias sobre las revoluciones de Venezuela. En: Anuario. Tomo IV-VI, vol. I, p.655, 1969. 
irremediable, más allá de que buena parte de esas acciones se hicieron en nombre del Rey. Aunque siguieron habiendo guerrillas realistas hasta la década de 1830 (Berrueta; Arismendi, 2011), la muerte de Boves en el campo de batalla y la restauración de Fernando VII, que no aprueba estas acciones, harán que el sueño de igualdad dejara de ser concebido en la cabeza de los pardos como susceptible de ser alcanzado con el Rey. Justo en ese momento Bolívar profundiza su oferta, como tierras a modo de soldada, ascensos, la eliminación jurídica del sistema de castas y la abolición de la esclavitud. Esto ayuda a que los republicanos ganen la guerra y a calmar la convulsión social, pero no resuelve el problema que el historiador Germán Carrera Damas ha llamado el de la ruptura de la estructura de poder interna, es decir "el complejo de relaciones interestructurales en función de las cuales se articulan los individuos, los grupos y las clases sociales, desde el punto de vista de su capacidad para influir en la marcha general de la sociedad" (Carrera Damas, 2006, p.27).

En efecto, la república que finalmente cuaja con la separación de la llamada Gran Colombia en 1830, vivó con distintos "rebeldes primitivos", como bandolerismo o cimarronaje (Mathews, 1977; Lynch, 1993; Rojas, 2009), que en la crisis de 1846 se articula en torno al Partido Liberal. De ese modo encontramos en Venezuela un hilo conductor entre el realismo popular y lo que podríamos llamar el liberalismo popular, cosa que inicialmente no pareciera posible si vemos la distancia entre un hombre como Fernando VII y los líderes del Partido Liberal, que provenían del sector realista que apoyó a Cádiz y después a la Revolución de 1820, y de un sector del bando republicano. Braulio Fernández puede darnos algunas pistas al respecto.

\section{LAS RAZONES de Don Braulio}

Lo primero que llama la atención en la Autobiografía de Braulio Fernán$d e z$ es la ausencia de una justificación de sus posturas políticas. ${ }^{6} \mathrm{O}$ no

6 FERNÁNDEZ, Braulio. Autobiografía de Braulio Fernández. En: FERNÁNDEZ, Braulio. ¡Alto esa patria! Hasta segunda orden. Autobiografía. Barcelona (Venezuela): Fondo Editorial del Caribe, 2010. 
consideró necesario defenderlas, por las razones que fuera; o si lo hizo sus hijos no lo incorporaron al folleto, o incluso es posible que nunca se haya preocupado demasiado en el asunto. Como hallamos en otros testimonios de los sectores populares durante la Independencia, por ejemplo en el famoso diálogo entre Bolívar y el Teniente Pedro Camejo, alias el Negro Primero, que reproduce José Antonio Páez en sus memorias; su aliciente fundamental parece haber sido el de salir lo mejor parado posible de aquella tempestad, más allá de que en las cosas en las que hace énfasis y se enorgullece, como en aquellas por las prefiere un silencioso rodeo, indican una valoración política de los hechos que no explicita. Ahora bien, salir lo mejor parado implicaba aprovechar cada oportunidad para ascender socialmente. Recordemos, para hacernos un parámetro, la respuesta que Camejo le da a Bolívar cuando le pregunta porqué había militado inicialmente en el bando realista:

-Señor, la codicia.

-¿Cómo así? preguntó Bolívar.

-Yo había notado, continuó el negro, que todo el mundo iba á la guerra sin camisa y sin una peseta y volvia (sic) despues (sic) vestido con uniforme muy bonito y con dinero en el bolsillo. Entonces yo quise ir tambien a buscar fortuna y mas que nada conseguir aperos de plata, uno para el negro Mindola, otro para Juan Rafael y otro para mí... ${ }^{7}$

Braulio Fernández, por su parte, parece que simplemente fue reclutado, por lo que no tuvo tiempo ni de pensar en la codicia, aunque como veremos la guerra también le trajo sus ventajas:

En 1810 entré a la guerra de la Independencia, siendo asistente de un Capitán llamado José Arboláis, sirviendo á la Patria: fuimos derrotados

7 PÁEZ, José Antonio. Autobiografía de José Antonio Páez. Caracas: Colección Libros, Revista Bohemia, s/f, p.214-125, 1867. 
en la batalla de Aragua de Barcelona, estando presente el mismo Capitán General Libertador. Como yo estaba en una edad muy temprana, me aterró tanto dicha derrota, que me rendí a los Godos; agradecido porque me salvaron la vida sin ultrajes, no quise traicionarlos en contra de mi gusto. El año 17 acompañé al General Aldama á tomar el Fuerte de Barcelona. ${ }^{8}$

Basta este párrafo para ofrecer una cara bastante distinta del relato que la Historia Patria ofrece. Es casi insólito que a tan pocos años de la aparición del texto épico de Venezuela heroica de Eduardo Blanco (1881), en la cual uno de los episodios de mayor exaltación emotivo es la matanza de patriotas que hizo el General Aldama tras rendir a la Casa Fuerte de Barcelona, en su retiro de Anaco Braulio Fernández haya dicho como si no fuera nada particular que él fue uno de aquellos soldados realistas que participaron en la acción. Incluso, parece que la recordaba con cierto orgullo, porque de los siete años que pelea como soldado del Rey, es lo único que consideraba (o consideraron sus hijos) algo digno de mencionar. Pero no sólo se solo eso: tres años antes de haber participado, en el bando de los perpetradores, en la matanza de la Casa Fuerte, lo hallamos como uno de los patriotas que peleaban bajo el mando de Bolívar en la batalla de Aragua de Barcelona. Eso significa que en una mirada tradicional, de héroes y villanos, Braulio no sólo pasa de lo un bando a otro con facilidad, sino que ni siquiera setenta años después parece darle importancia al asunto. A este respecto, su retorno al ejército patriota es aún más notable:

El año 18 el Teniente Rey General Juan Pablo Morillo, del Cuartel General de Valencia, mandó oficios fisonómicos para todos los pueblos, pidiendo tres hombres de cada uno para su guardia de honor, que no fueran de color oscuro, bermejo, vitola, ñato, ni de mala voz. En San José de Unare formaron mil y pico de hombres y nos pusieron a hacer ejercicio. Un Secretario cumanés llamado Francisco Rodríguez,

8 FERNÁNDEZ, Braulio. Autobiografía de Braulio Fernández, p.19. 
con el oficio á la vista estaba fisonomisándonos, y a mí fue uno de los que apartaron, con el título de Teniente. Me mando el Comandante Torrealba a la madrina de cuatrocientas bestias para que apartara una mula que me gustara y la pusiese en cuerda hasta segunda orden: yo escogí un macho colorado que hoy valdría 400 fuertes. Varios oficiales se le acercaron a Torrealba y le dijeron que porqué mandaba a Braulio. - Le contestó: - no sean sonsos yo debo mandar a uno que no se diga. Los oficiales dichos llenos de sentimiento por mi separación para Valencia, entonces se acercaron a mí y me dijeron: somos de parecer que te alistes de todo, te despidas y te vayas á defender la Patria, que nosotros tenemos amigos allá y te recomendaremos. Pero haya hoy no sé la causa por qué no se efectuó el viaje. Desengañado por sí mismo que era torpeza acompañar más a España, el año 21 determiné con el Comandante Torrealba presentarnos al constante General José Tadeo Monagas, en el Carito Guárico...9

Veamos primero lo de la búsqueda de una guardia de honor para Pablo Morillo. El jefe del ejército expedicionario mandado desde España para reconquistar Venezuela y Nueva Granada en 1815. La selección se parece más bien un certamen de belleza o a un casting publicitario. Buscar a alguien que "que no se diga...", expresión ya en desuso pero común hasta hace relativamente poco. Incluso se destina un funcionario para que haga el examen fisionómico y encuentre jóvenes oficiales que no fueran "de color oscuro, bermejo, vitola, ñato, ni de mala voz", es decir, tan blancos y bien parecidos (al menos no narigudos o ñatos) como fuera posible, con buena voz (no hemos logrado determinar en qué sentido usa lo de vitola) y, por alguna razón difícil de discernir, que no fueran bermejos. A lo mejor querían evitar a esa clase de pardos y mulatos con cabello rojizo a los que en Venezuela popularmente se les llama bachacos. Quedan determinados así algunos fenómenos muy de la Venezuela actual, como el culto a la belleza, la forma en la que ésta se asocia con la raza y el hecho de ser blanco y bonito (muchas veces,

9 FERNÁNDEZ, Braulio. Autobiografía de Braulio Fernández, p.20. 
bonito sólo por ser blanco) ayude a cualquiera a ascender siguen siendo aspectos muy presentes en la sociedad venezolana. En segundo lugar, es muy significativa la razón por la que inicialmente piensa dejar al ejército realista y sobre todo el modo en el que planea hacerlo: porque lo van a enviar a otra región y a través de unos compañeros de armas que dicen ¡tener amigos en el bando contrario, con quienes pueden recomendarlo! Lo del cambio de región podía deberse a lo que entonces llamaban las patriecitas, eso entornos en los que los soldados habían estado toda su vida y de los que no querían salir por nada. No es irrelevante que, ya en el Ejército Libertador, mientras combate en Caracas, le dice a sus paisanos orientales: "el que muera aquí va a resucitar en su tierra". ${ }^{10}$ No tenemos idea de dónde pudo haber sacado esa suerte de promesa de resurrección, que recuerda un poco a la que se les hace a los yihadistas, pero demuestra al menos dos cosas: el enlazamiento entre el pensamiento político y la religiosidad populares; y el nivel de angustia que tenía cualquiera de aquellos hombres de no volver a ver a su patriecita más nunca. "Y así espero en Dios nos vuelva a llevar a nuestro Oriente", 11 ruega Fernández. No obstante, tal vez pudo haber habido otra razón por la que su envío a otra parte podría haberlo angustiado: el peligro de que fuera mandando a la Nueva Granada o a las Antillas, dentro del programa general de Morillo de desarticular a las fuerzas criollas que habían peleado con Boves. Sobre todo a los de color, más violentos y peligrosos. Si Braulio logró pasar el casting, seguramente era blanco; pero tenía en su hoja de servicios cosas como la de la Casa Fuerte y él mismo recordaba que, siendo ya patriota, "a la media hora de la batalla [de Caracas, en 1821], me dispararon un tiro por una ventana y me le pasaron la copa á mi sombrero. Inmediatamente me acerqué á la casa y con la punta de mi lanza le hice una sá la pared con la mala idea de que si ganábamos degollar, á los que estuviesen adentro". ${ }^{12}$ Los habitantes tuvieron la suerte de que perdiera aquel combate, pero da un retrato del

10 FERNÁNDEZ, Braulio. Autobiografía de Braulio Fernández, p.39.

11 FERNÁNDEZ, Braulio. Autobiografía de Braulio Fernández, p.26.

12 FERNÁNDEZ, Braulio. Autobiografía de Braulio Fernández, p.39. 
hombre y del modo de hacer guerra incluso después de los tratados de regularización del conflicto firmados entre la Gran Colombia y España el año anterior, y que son considerados un antecedente del derecho internacional humanitario (Alfaro Pareja, 2016). En cualquier caso, lo del regionalismo es mucho menos llamativo que el plan de deserción. Eso de que unos compañeros de armas te consigan unas recomendaciones para ingresar al ejército contrario, debe ser un hecho muy excepcional en los anales de la historia militar. Habla de lo porosos que fueron los bandos en una guerra que nunca dejó de ser completamente civil, ni siquiera con la llegada de los diez mil soldados del Ejército Pacificador de Morillo. Así se trataba de un mismo pueblo matándose entre sí, que las relaciones sociales trascendían los ejércitos.

Lamentamos que no explique Braulio Fernández porqué se "desengañó" de servir por España. Cuentan que cuando toman unos prisioneros realistas, Bermúdez les pregunta: “ ¿quieren irse para sus casas ó seguir la libertad? - Le contestaron: seguir la libertad, mi General". ${ }^{13}$ La libertad era para ellos una bandería concreta, un ejército vencedor al que unirse cuando el suyo se volvía trizas en todas partes, ¿pero significaba algo más? "Vengo a sembrarles en la fuente de Caracas el árbol de la libertad", dice Bermúdez en otro momento. ${ }^{14}$ Más allá del hecho de que ahora vendrían las autoridades de la Patria (cosa que en el lenguaje de la época equivalía a república y a gobierno de venezolanos y no de españoles), ¿qué podía ser la libertad para Fernández? “AAbajo la Corona y arriba Venezuela!", remató Bermúdez. ${ }^{15}$

Otro dato revelador es la absoluta confusión de los cargos políticos que demuestra Fernández. Salvo el del Rey, nunca pareció haber entendido en qué consistía el resto de los mismos. A Bolívar lo llama Capitán General Libertador, fundiendo a la mayor autoridad colonial con la republicana acaso para entender él mismo y hacer entender a sus interlocutores del lugar que había ocupado en la sociedad. A Carlos

13 FERNÁNDEZ, Braulio. Autobiografía de Braulio Fernández, p.24.

14 FERNÁNDEZ, Braulio. Autobiografía de Braulio Fernández, p.26.

15 FERNÁNDEZ, Braulio. Autobiografía de Braulio Fernández, p.26. 
Soublette lo titula "primer presidente de Venezuela", en un momento en el que Venezuela no existía porque formaba parte de la Gran Colombia y Soublette era sólo un jefe de su ejército. Tal vez una buena parte de los venezolanos no estuvieran muy bien enterados de la unión grancolombiana hasta que después de Carabobo entraron en ella. El disgusto que generó desde el principio y que en cinco años llevó a una rebelión secesionista alimenta esta idea; pero que sesenta años después uno de sus protagonistas siguiera sin tenerlo claro, es significativo. Para el anciano Don Braulio, su ejército nombró a Soublette presidente en 1821, ergo, era su presidente y así lo dice una y otra vez. Cúcuta o Bogotá no son ni siquiera realidades lejanas, simplemente no existen en su relato. En 1846 es de los venezolanos que se alzan para defender la candidatura de Antonio Leocadio Guzmán, nuevo portavoz de las ideas de igualdad. Es un ejemplo especialmente claro del trasvase del realismo popular al liberalismo popular. El punto viene porque para el autor se trataba del General Antonio L. Guzmán, quien, salvo un nombramiento juvenil que le otorgó Bolívar, nunca fue militar ni participó en la política bajo esos términos. Tal parece que en la cabeza de Don Braulio, así como el Libertador debía ser un Capitán General para que mandara como lo hacía, Guzmán debía ser un general para merecer su obediencia. ${ }^{16} \mathrm{El}$ testigo de la jefatura militar pasado de la autoridad colonial al caudillo local, acaso la gran metáfora de la independencia.

Hemos llamado a este artículo "las razones de Don Braulio", copiándonos un poco de la antología de documentos de José Antonio Páez a la que su compilador, Edgardo Mondolfi, tituló Páez: las razones del héroe (1990), pero después de analizar su autobiografía el título parece una oferta engañosa. Sólo podemos decir que lo de "las razones de Don Braulio" es una meta a cumplir, el planteamiento de un problema: ¿cuáles fueron las razones de aquel veterano de tantas guerras y tantos bandos? Aunque no lo diga, tal vez aunque no lo supo conscientemente nunca, se pueden hacerse algunas hipótesis con las que cerrar este texto.

16 FERNÁNDEZ, Braulio. Autobiografía de Braulio Fernández, p.19; p.26; p.42. 


\section{UN ESCLAVO POR UNA MULA, A MODO DE CONCLUSIÓN}

Lo primero que viene a la mente después de leer la autobiografía de Fernández, es que las lamentaciones de las elites de la independencia por su pueblo, tenían algún asidero: quien debió ser uno de los soldados mejor informados del ejército (era, al menos, alfabeto), ni parecía especialmente preocupado por las cuestiones doctrinarias, ni sabía exactamente bien cómo funcionaba la institucionalidad que se fundaba. Lo de Bolívar como Capitán General, lo de Soublette como presidente de un país que no existía, pero que gobernaba, y lo de Guzmán como general, demuestra el modo en el que las referencias de los hombres como Don Braulio eran muy distintas a las de las leyes y congresos. Tres cosas parecían tener claras: que la máxima autoridad es el Capitán General, que vivía y siempre había vivido en algo llamado Venezuela y que los líderes son los generales del caudillismo. Si lo vemos bien, estaba mucho mejor encaminado en su diagnóstico del país que los letrados que se lamentaban en sus curules y sus cátedras. Tenía razón, los nuevos jefes ocupaban el lugar de los Capitanes Generales, pero con más poder ya que no dependían de un Rey; Venezuela nunca desapareció como identidad dentro de la Gran Colombia, y quienes así lo sentían lucharon hasta hacerla revivir en 1830; y los caudillos eran los nuevos amos del país. Sería ignorante Don Braulio de muchas cosas, pero no en lo que hacía falta para sobrevivir.

Es una lástima que no abunde en su realismo, pero es probable que la razón fundamental haya sido la que alegó, sin necesidad de buscarle cinco patas al gato: lo reclutan los patriotas, es derrotado en una batalla, lo tratan bien y agradecido los acompaña hasta que ya tienen la guerra perdida y, sobreviviente nato ("mi cuerpo no fue herido ni fui prisionero jamás", afirma), ${ }^{17}$ se monta en la nueva ola. El elemento religioso de aversión a lo que Pedro Camejo llamó la diablocracia, ${ }^{18}$ que todos los ob-

17 FERNÁNDEZ, Braulio. Autobiografía de Braulio Fernández, p.42.

18 PÁEZ, José Antonio. Autobiografía de José Antonio Páez. Caracas: Colección Libros, Revista Bohemia, s/f, p.215, 1867. 
servadores del momento señalan en el realismo, pudo haber tenido en su pensamiento. Era un hombre muy religioso, cosa que evidentemente le ayudó a sobrevivir la guerra: atribuye "a mi abogada Santa Rita" haberse librado de un tiro y la idea de resucitar en "nuestro Oriente" debió ser suya también; pero no dice nada de oponerse a la república por razones de fe. ${ }^{19}$ En lo que sí hay una evidencia del criterio para escoger sus opciones es la "codicia" alegada por Camejo. Salir de abajo, conseguir cosas en la guerra, alcanzar otro estatus era una aspiración general. Fernández es blanco y, por lo visto, bastante guapo y despierto; Camejo es negro y liberto, es decir, sus puntos de partida no son los mismos, pero dentro del orden colonial están más bien hacia la base de la pirámide y los dos buscan ascender a punta de lanzazos. Camejo nada menos que se hace libre y se convierte en un héroe de la patria, acaso la concesión de la Historia Patria para que se identificaran en ella los afrodescendientes. Fernández ni viene de tan atrás, ni llega tan lejos, pero el hecho de que sus hijos hayan impreso un folleto con sus memorias indican que su familia logró bienes de fortuna en el camino. En ambos casos, si esas aspiraciones se cubrían peleando por el Rey, muy bien; si eso ya no era posible, pues se cubrirían con Bolívar o con Antonio Leocadio Guzmán. No en vano estamos hablando de las tres figuras políticas más importantes de Venezuela hasta 1870, cuando emerge el todopoderoso Antonio Guzmán Blanco, hijo de Antonio Leocadio.

Cerremos con una anécdota que nos dice bastante bien cómo la guerra permitía ascender. Retirándose de Caracas en 1821, Fernández se encuentra con Bermúdez: "le entregué doce mulas y yo me quedé con una parda que valía 500 pesos; al fin se la vendí al Capitán Arbeláis por un criado de quince años y un caballo escogido dentro de veinte". ${ }^{20}$ ¡Vaya que era valiosa la mula! Quinientos pesos era una fortuna, en efecto, el valor de un esclavo, que debía rondar los trescientos, y de un caballo. Lo que se quiere destacar con esta transacción, es que Fernández pudo regresar a su casa, incluso después de una derrota, con un esclavo y un

19 FERNÁNDEZ, Braulio. Autobiografía de Braulio Fernández, p.32.

20 FERNÁNDEZ, Braulio. Autobiografía de Braulio Fernández, p.34. 
caballo, más de todo lo soñado jamás por Camejo. Comoquiera que, según cuenta, su suegro y su hermanos también estaban en el Ejército Libertador, si cada uno lograba algo similar y después como pago de sus haberes se les daba alguna finca, la Patria estaba cumpliendo con eso su propósito.

¿Significa que no hubo otros valores, que a lo mejor hubo realistas y patriotas del pueblo con razones más ideológicas? De ninguna manera, los hubo (como lo demuestra la compilación de Bolívar y otros, 2010); pero sí que este aliciente por ascender jugó un papel en el que hay que tomar muy en cuenta para entender la historia venezolana. ¿Esto le quita mérito a la Independencia como revolución? No, las revoluciones están para cambiar las cosas y, al menos idealmente en las liberales y democráticas, ampliar los derechos. Que un esclavo se haga libre y que un hombre del pueblo se vuelva propietario no son cambios menores. Y así además parecieron vivir y entender el proceso los sectores populares. En esa clave hay que problematizarlo, sin negar otras variables posibles ni forzar las cosas para los reclamos de la política actual.

\section{REFERENCIAS BIBLIOGRÁFICAS}

ALFARO PAREJA, Francisco. La historia oculta de la independencia de Venezuela. De la guerra idealizada a la paz imperfecta. Caracas, Alfa, 2016. BERRUETA, Jorge; ARISMENDI, Álvaro. La fiel guerrilla del rey. El accionar guerrillero en la Provincia de Caracas como factor determinante en los planes de reconquista española (1821-1831). Caracas: Archivo General de la Nación/Centro Nacional de Historia, 2011.

BOLÍVAR, Eillen y otros (Coord.). Memorias de la insurgencia. Caracas: Archivo General de la Nación/Centro Nacional de Historia, 2010.

CABALLERO, Manuel. Gómez, el tirano liberal. 2da. edición. Caracas: Monte Ávila Editores Latinoamericana, 1995.

CAÑIZALEZ GUÉDEZ, Emigdio. El indio en la Guerra de Independencia. Caracas: Universidad Central de Venezuela, 1993.

CARRERA DAMAS, Germán. Boves, aspectos socioeconómicos de la guerra de independencia. 2da. edición. Caracas: Monte Ávila Editores, 1991. 
CARRERA DAMAS, Germán. El culto a Bolívar. Esbozo para un estudio de la historia de las ideas en Venezuela. Caracas, Universidad Central de Venezuela, 1970.

CARRERA DAMAS, Germán. Formulación definitiva del proyecto nacional: 1870-1900. Caracas: Cuadernos Lagoven, 1988.

CARRERA DAMAS, Germán. La crisis de la sociedad colonial en Venezuela. Caracas: Monte Ávila Editores, 1983.

CARRERA DAMAS, Germán. Casos de continuidad y ruptura: génesis teórica y práctica del proyecto americano de Simón Bolívar. In: CARRERA DAMAS, Germán. Historia general de América Latina. Volumen V. Madrid: Ediciones UNESCO/Editorial Trotta, 2003. p. 287-314.

CARRERA DAMAS, Germán. Venezuela, proyecto nacional y poder social. 2da. edición. Mérida (Venezuela): Universidad de los Andes, 2006.

CASTELLANOS RUEDA, Rocío; CABALLERO ESCORCIA, Boris. La lucha por la igualdad. Los pardos en la independencia de Venezuela, 1808-1812. Caracas: Archivo General de la Nación/Centro Nacional de Historia, 2010.

CASTRO LEIVA, Luis. De la Patria Boba a la teología bolivariana. Caracas, Monte Ávila Editores, 1984.

ECHEVERRI, Marcela. Los derechos de indios y esclavos realistas y la transformación política de Popayán, Nueva Granas (1808-1820). Revista de Indias, vol. XLIX, n. 246, p.45-72, 2009.

FARNCESCHI, Napoleón. El culto a los héroes y la formación de la nación venezolana. Caracas: s/n, 1999.

GUERRERO, Carolina. Una tercera especie de república: de los antiguos, de los modernos y la república a la manera de Bolívar. Anuario de estudios bolivarianos. Año X, n. 11, p.219-248, 2004.

GUTIÉRREZ RAMOS, Jairo. Los indios de Pasto contra la república (1809-1824), Bogotá: Instituto Colombiano de Antropología e Historia, 2007.

HERNÁNDEZ GONZÁLEZ, Manuel (Editor). Entre la insurgencia y la fidelidad. Textos canarios sobre la independencia venezolana. Tenerife: Ediciones Idea, 2010.

LOMBARDI, Ángel. Banderas del Rey: la visión realista de la independencia. Maracaibo: Universidad Cecilio Acosta, 2006. 
LÓPEZ, Isaac. La élite coriana en el proceso de Independencia. El caso de la familia Garcés. Caracas: Academia Nacional de la Historia, 2010.

LOVERA, Elina Reyes. De leales monárquicos a ciudadano republicanos. Coro, 1810-1858. Caracas: Academia Nacional de la Historia, 2007.

LYNCH, John. Caudillos en Hispanoamérica. Madrid: Mapfre, 1993.

LYNCH, John. Simón Bolívar. Barcelona: Crítica, 2006

MATTHEWS, Robert. La violencia rural en Venezuela, 1840-1858. Caracas, Monte Ávila Editores, 1977.

OVALLES, Caupolicán. Antología de la literatura marginal. Caracas: Monte Ávila Editores, 1977.

PELLICER, Luis Felipe. Memorias de la Insurgencia. Una historia del pueblo, con el pueblo y para el pueblo. En: BOLÍVAR, Eillen y otros (Coord.). Memorias de la insurgencia. Caracas: Archivo General de la Nación/Centro Nacional de Historia, 2010. p.V-XII.

PERNATELE TÚA, Carlos. El mito del "Bravo pueblo". En: QUINTERO, Inés (Coord.). El relato invariable. Independencia, mito y nación. Caracas: Editorial Alfa, 2011. p.57-93.

PINO ITURRIETA, Elías. El divino Bolívar. Ensayo sobre una religión republicana. Madrid, Catarata, 2003.

PINO ITURRIETA, Elías. Ideas sobre un pueblo inepto: la justificación del gomecismo. En: Pino Iturrieta, Elías (Comp.), Juan Vicente Gómez y su época. 2da. edición. Caracas: Monte Ávila Editores, 1993. p.187-201.

PINO ITURRIETA, Elías. País archipiélago. Venezuela, 1830-1858. Caracas, Fundación Bigott, 2001.

ROJAS, Aura. Insumisión popular, 1830-1848. Caracas: Centro Nacional de Historia, 2009.

SORIANO DE GARCÍA PELAYO, Graciela. Venezuela, 1810-1830: aspectos desatendidos de dos décadas. Caracas: Cuadernos Lagoven, 1988.

STRAKA, Tomás. De la "República aérea" a la "República monárquica”. El nacimiento de la república venezolana. En: STRAKA, Tomás; Agustín Sánchez-Andrés y Michael Zeuske (Comp.). Las independencias de Iberoamérica. Caracas: Fundación Empresas Polar/UCAB/UMSNH, 2011. p.405-482.

STRAKA, Tomás. La épica del desencanto. Bolivarianismo, historiografía y política en Venezuela. Caracas, Editorial Alfa, 2009. 
STRAKA, Tomás. La voz de los vencidos, ideas del partido realista de Caracas. 1810-1821. Caracas, Universidad Central de Venezuela, 2000.

STRAKA, Tomás. Venezuela: la era de los gendarmes. Caudillismo y liberalismo autocrático, 1831-1936. Caracas: Fundación Rómulo Betancourt, 2013.

TORRES, Anta Teresa. La herencia de la tribu. Del mito de la independencia a la Revolución Bolivariana. Caracas, Editorial Alfa, 2009.

URBANEJA, Diego Bautista. Bolívar, el pueblo y el poder. Caracas: Fundación para la Cultura Urbana, 2004.

URBANEJA, Diego Bautista. "Introducción histórica al sistema político venezolano”. Politeia, n. 7, p.11-59, 1978.

URUEÑA CERVERA, Jaime. Bolívar republicano. Fundamentos ideológicos e históricos de su pensamiento político. Primera reimpresión. Bogotá: Ediciones Aurora, 2007.

VAAMONDE, Guastavo. Los novadores de Caracas. La Suprema Junta de Gobierno de Venezuela, 1810-1811. Caracas: Academia Nacional de la Historia/Fundación Bancaribe, 2009.

VAN YOUNG, Eric. Entrevista en CHUST, Manuel (Ed.). Las independencias iberoamericanas en su laberinto. Valencia: Univeritat de Valéncia, 2010. p.365-373. 